Estudios Románicos, Volumen 28, 2019, pp. 281-293

ISSN: 0210-491

eISSN: 1989-614X

DOI: https://doi.org/10.6018/ER/372861

\title{
SCHUBERT, JUAN BENET Y LA MÚSICA DE LA RESIGNACIÓN
}

(Schubert, Juan Benet and the music of resignation)

\author{
Sandrine Lascaux* \\ Université du Havre (GRIC -ERIAC)
}

\begin{abstract}
The literature of Juan Benet attempts to transport the reader beyond the bounds of reason by means of the arts, and most especially in the relation that binds it to music. Following Schopenhauer and Nietzsche who considered music to be the only art capable of transmitting pure affect without any intellectual mediation, Benet seeks the limits of language and effects persistent sentence modulations with a view to accessing the music of the soul. In this respect, his essay Door of the Earth elucidates the close affiliation between his work and the "music of resignation" which defines Schubert's later work.
\end{abstract}

Keywords: Literature; Music; Modulation; Benet; Deleuze; Schubert.

Resumen: La literatura de Juan Benet intenta superar la razón mediante las artes y en particular gracias a la relación que establece con la música. Siguiendo los pasos de Schopenhauer o de Nietzsche que consideran la música como el único arte susceptible de convocar el afecto puro sin ningún tipo de mediación intelectual, Benet busca los límites del lenguaje con operaciones constantes de modulaciones frásticas para alcanzar una música íntima. En este sentido, el ensayo Puerta de tierra permitiría entender la estrecha relación que une la obra benetiana con la música de la resignación compuesta por Schubert en sus últimas obras.

Palabras claves: Literatura; Música; Modulación; Benet; Deleuze; Schubert.

\section{Introducción}

Proponemos una reflexión sobre la obra de Juan Benet a partir de elementos que nos parecen participar a la relación que tiene el novelista, conocido por sus obras

*Dirección para correspondencia: Sandrine Lascaux, Universidad de Le Havre, Departamento de Lenguas Románicas, 25 rue Philippe Lebon 76600, Le Havre, France. [sandrine.lascaux@gmail.com]. 
herméticas y difíciles, con el arte musical. Si como lo observaron los críticos, es la imagen la que domina la escritura benetiana- como lo demuestra también su teoría narrativa que desde La inspiración y el estilo sentó las bases de la superioridad de una dimensión visual capaz de acentuar la intensidad del texto hasta convertirlo en una larga proyección de imágenes inmóviles - poco se comentó la relación estrecha que el estilo mantiene con la música. Sabemos que uno de sus textos mayores, y sin duda el más enigmático, Un viaje de invierno remite explícitamente a la obra de Schubert Wintereisse. Resulta así que toda la obra de Benet quiere lograr una emoción pura para adentrarse mejor en las pasiones humanas y emanciparse de la razón, haciéndose, en ese objetivo, muy musical.

Veremos, en un primer momento, como Benet busca ir más allá del lenguaje y convocaremos la noción de "modulación" utilizada en particular en la filosofía de Deleuze. Schubert es una referencia musical fundamental para Benet y a la luz de sus ensayos comprendemos que Schubert supo alcanzar en los últimos momentos de su vida, una música de la renuncia que expresaba una soledad interior total frente a la inminencia de la muerte. A continuación, demostraremos que la música en la obra benetiana tiene un vínculo directo con la problemática de la interlocución literaria. ¿A quién se dirige el texto literario? Benet rechaza la idea de que el texto literario deba escribirse para satisfacer al público al afirmar que se escribe ante todo para sí mismo. Si también se escribe para los demás para llegar a cierta comunicación, no es para un público anónimo sino para un ser singular que funciona como un doble y con el que se va a compartir una relación íntima.

\section{Lenguaje y música}

El estilo literario de Juan Benet crea tensiones inéditas en el lenguaje para confrontarlo con sus propios límites haciendo la experiencia de su imposibilidad. El texto benetiano nos da a oír en sus intersticios, la fuerza sonora de lo no-sonoro, primero, porque al convocar al grito y su desgarramiento se escribe explícitamente el silencio y esto en cada página, además porque la lengua se orienta hacia su propia extremidad. Si se suele decir que el estilo de Benet es visual y plástico, en realidad es ante todo eminentemente sonoro. Como lo sugiere Deleuze, un gran libro siempre es el revés de otro libro: un libro que sólo se puede escribir en el alma, con silencios y lágrimas. Deleuze, que nunca escribió sobre la música pero que abordó esta cuestión a partir de la escritura literaria, explica como el estilo literario es capaz de inventar una lengua extranjera en la lengua: "[...] el escritor, como dice Proust, inventa dentro de la lengua una lengua nueva, una lengua extranjera en cierta medida" y añade: "El estilo es auditivo puro".

El límite no está fuera del lenguaje, sino que es su afuera: se compone de visiones y audiciones no lingüísticas, pero no sólo el lenguaje hace posibles. También existen una pintura y una música propias de la escritura, como existen efectos de colores y de sonoridades que se elevan por encima de las palabras. Vemos y oímos a través de las palabras, entre las palabras. (Deleuze; Guattari 1996: 9) 
La relación con lo musical podría señalar este "hay" de Levinas, concepto que se refiere al agotamiento imposible de la expresión. Esta música que no es instrumental sino literaria se basa primero en una sintaxis cuyo principal objetivo consistiría en crear y favorecer una tensión anormal en el flujo frástico. Según Deleuze y Guattari (1980), lo que se llama estilo, que puede ser la cosa más natural del mundo, es precisamente "el proceso de una variación continua". Toda materia que se somete a una variación (o una modulación) tiende a una forma de musicalización. La tensión sintáctica introduce la problemática de una "agramaticalidad" que indica el límite que separa el lenguaje de la música: "el lenguaje en su totalidad tiende hacia un límite «asintáctico», «agramatical», o que comunica con su propio exterior" (Deleuze; Guattari 1996). Por consiguiente, mediante la sintaxis, se trata de instalar "tensores" que crean líneas de modulaciones para someter la lengua a un desequilibrio perpetuo.

Esto nos permite introducir un primer cuestionamiento, Benet no es lingüísticamente subversivo, es decir que no adopta posiciones formales "destructivas" como las de Joyce, Artaud, Khlebnikov. Si su prioridad consiste bien en garantizar la gramaticalidad de los enunciados, esto no permitirá necesariamente obtener la legibilidad de los textos más complejos (Una meditación o Saúl ante Samuel, por ejemplo). Esto no significa que no flexione la lengua para crear un lenguaje propio, otro lenguaje. Cumplir las normas y jugar con combinatorias a partir de la acumulación de sistemas tensivos como la puntuación, los paréntesis, la negación para convertir el texto en una matriz combinatoria infinita es un método fenomenal para desmultiplicar sin discontinuidad los desequilibrios de todos tipos incluso si se refuerza la cohesión frástica y que, por consiguiente, se impide el acceso al conjunto del relato.

Lo que se busca en tales casos es un lenguaje activo e intensivo, al borde del silencio que se desarrolla a partir de una modulación continua (sintáctica, semántica, enunciativa) hasta provocar una forma de delirio lingüístico: "[el escritor] saca la lengua de los caminos trillados, la hace delirar" (Deleuze; Guattari 1996: 9). Finalmente podemos decir que lo importante no es que Benet respete la sintaxis sino que le imponga una variación personal que va a modificar la relación con la norma misma sometiéndola a un orden que se prevé pero que en general no se utiliza. El ampliar el potencial combinatorio de la lengua conduce el texto (y especialmente Saúl ante Samuel) hasta un agotamiento que nunca se puede realizar por completo y que puede comprenderse como un devenir - música de la escritura literaria:

Escribir indudablemente no es imponer una forma (de expresión) a una materia vivida.La literatura se decanta más hacia lo deforme, o lo inacabado, como dijo o hizo Gombrowicz). Escribir es un asunto de devenir, siempre inacabado, siempre en curso, y que desborda cualquier materia vivible o vivida. (Deleuze; Guattari 1996: 11)

Los textos de Benet son procesos que pueden considerarse según un modo dialógico que favorece la integración de múltiples discursos exógenos. Por ejemplo, la filosofía se une a la dimensión literaria para dinamitar la categoría del "concepto" mezclándola 
con las del "percepto" y del "afecto". De la misma manera, las artes-y la música, arte por excelencia -participan de un devenir de la literatura como fuerza de transformación del lenguaje mismo.

Cuando en sus ensayos Benet habla de la música, se interroga primero sobre la coexistencia del texto y de la música en el drama musical subrayando en La moviola de Eurípides que la principal ventaja del disco (como soporte) estriba en suprimir lo que acompaña la música.

Suprimir el intérprete significa suprimir el montaje, la puesta en escena y el drama musical con su sinestesia. El intérprete con sus gestos humanos no puede sino perjudicar a la sutileza de la melodía, "no puede evitar transmitir con el gesto la experiencia por la que está pasando su alma":

La gran ventaja del disco es que conserva la interpretación y suprime al intérprete. $\mathrm{Y}$ es justo que el disco exija un cierto precio por semejante favor [...] : nada menos que suprimir al intérprete, el montaje, el escenario o, en una palabra el drama musical que, para cierta actitud cenestésica, da lo mismo que sea una representación a todo trapo de una ópera o la interpretación de una partita por un solista.

[...] todo intérprete del drama musical es, por lo general, un mal actor que con su actuación no hace [...] sino empañar una audición que encomendada a gestos y palabras pierde buena parte de su poder para transportar la mente a un terreno donde no se den otras condiciones sensoriales que las de la música y en el que no existe otro conductor que el propio objeto de arte. (Benet 1982: 14)

La naturaleza del drama musical es problemática; para que exista cierta cualidad es necesario que un arte domine a los otros. Por otra parte, la asociación de la música y del lenguaje verbal es compleja. La única excepción residiría en la música sagrada (misa, pasión, oratorio) pues en este caso el objetivo consiste en superar, adoptando una forma ritualizada, el drama gracias al velo del misterio divino. El texto del drama sagrado no contiene el drama, es la expresión de la palabra divina que contiene en ella"todo el contenido anterior a la tragedia" (Benet 1982: 16). En este sentido no sólo el lenguaje es superfluo sino también atemporal, eterno, como lo es el drama, y por consiguiente será incomprensible, expresado en latín o en otro idioma. El modo armónico superará la articulación de lo textual y de lo musical.

Si la frase dice algo no hace más que estorbar a la música y sólo cuando el drama literario pertenece a la memoria y se puede prescindir de la intelección por la audición directa puede la atención dirigirse al disfrute de esa difícil y desigual soldadura. (Benet 1981: 19-21)

Lograr este orden armónico significa convocar el afecto puro sin mediación intelectual y es precisamente lo que busca Benet con la escritura. El diálogo de la literatura con las artes incluso con la música se inscribe en esta problemática. Si se consideran los fragmentos exaltados que dedica a la música, Benet se inscribe en la tradición de 
filósofos como Nietzsche o Schopenhauer que ven la música como un arte superior en el que se esconde el obstáculo secreto del pensamiento. Si como Schopenhauer, Deleuze afirma la existencia de una jerarquía de las artes propone al mismo tiempo asimilar todas las disciplinas artísticas:

Todo es cuestión de línea, entre la pintura, la música y la escritura no hay una gran diferencia. Estas actividades se distinguen por sus sustancias, sus códigos y sus respectivas territorialidades, pero no por la línea abstracta que trazan, que pasa entre ellas y las arrastra hacia un común destino (Deleuze; Parnet 2013: 85),

\section{Literatura, música e introspección}

El proyecto benetiano consistiría entonces en descubrir lo que finalmente une las líneas, los colores, los sonidos y las palabras. Su proyecto necesita también que se tome en cuenta el deseo de introspección que reivindica desde sus primeras obras. Como novelista lo que le preocupa es ante todo contarse la historia que le habría gustado escuchar; solo él puede hacerlo. En una carta del 11 de junio de 1965, Benet evoca el origen de la función narrativa, el deseo profundo del que escribe y la supuesta proyección del lector en lo que lee: la posibilidad de encontrar un interlocutor real. Explica que el narrador nace en los primeros años de la vida cuando el niño lee relatos de aventuras en los que lo más importante "es el cuento que uno se cuenta a sí mismo". Este tipo de novela se limita sin embargo a escenificar une forma de yo mejorado que encarna otra versión del yo de la vida cotidiana. En ese momento es cuando nace una función narrativa que se basa más en el oír y el ver que en el decir. Toma el ejemplo de la novela de James Thurber, La vida secreta de Walter Mitty (1942), una novela mediocre magistralmente llevada al cine (cinco años más tarde) por Norman Z. McLeod y subraya:

Estoy seguro de que nada le habría complacido más a tu amigo Walter que sentarse en una butaca para escuchar o ver su relato, narrado con los mismos colores y temas pero puestos en labios de una tercera(segunda, más bien) persona. Pero lo que pasa es que no habrá - ni hay nunca - ese narrador que cuente la clase de relato que Walter quiere oír. Así que lo tiene que hacer, incluso a regañadientes. (Benet 2003: 75)

El escritor se convierte en el único interlocutor válido, es el quien conoce la música que quiere escuchar. Originalmente no es un narrador que busca un oído comprensivo sino un oído preciso y único que necesita un relato. En otros términos, Benet realiza una teorización de la autonomía del texto literario. La problemática de la interlocución y finalmente la del público ya no tienen sentido:

¿Es posible olvidarse por completo del lector? Es posible, puestos a distraer, que un individuo con actitudes un tanto selectivas y exquisitas esté pensando en el bien que le va a parecer su libro a fulano, a un amigo en lo que confía y con el que coincide 
en muchas cosas. Pero con el público en sí uno no se puede sentir identificado ni compenetrado, es una abstracción, no existe, no tiene cara, ni nombre propio, ni expresa sus gustos (Benet 1997: 256).

\section{Una lectura benetiana de las últimas obras de Schubert}

En su libro sobre Kafka, Deleuze y Guattari explican que el objetivo del escritor reside en obtener un sonido puro intenso, una pura materia sonora.Esta música no deriva del manierismo sintáctico, es una música del alma, una música interior. En este sentido, se puede pensar en la sonata de Vinteuil que despierta en Swann el amor incondicional por Odette, una pequeña frase repetitiva de cinco notas que trasciende la relación de estos dos personajes hasta convertirse en el aire nacional de su amor. Con esta unidad musical, Proust ofrece una visión intima de la música que logra mostrar la eternidad de las sensaciones.

Cuando en Puerta de Tierra, Benet relata su visión del último periodo de la vida de Schubert, lo hace en términos casi idénticos a los que utiliza para evocar su experiencia de la interlocución literaria como problema literario. Comprendemos que se identifica con Schubert. El músico, en los últimos momentos de su vida cambia de estilo musical y entra en su periodo "destructivo". Cuando la enfermedad está a punto de llevárselo, se refugia en sí mismo y opta por no tomar en cuenta al público.

Todo parece indicar que - muy contra su voluntad - se vio empujado a escribir dos clases de música, en lo que al aplauso se refiere: la que había de conocerlo en vida de su autor y la que - tan seguro estaba de ello que no se molestó en mostrarla a nadie - por el momento sólo era apreciada por él mismo (Benet 2003:96).

Consciente de que no puede cortar con su arte (« un quehacer inextinguible que durará tanto como el hombre ») busca la paz en el aislamiento:

Ya sólo quedaba por conseguir la paz interior; su situación era parecida a la de ese país en decadencia que, tras una guerra imperial desastrosa, tras la pérdida de todo prestigio internacional, quiere retraerse hacia sí mismo para poner en orden los asuntos de casa (Benet 2003:97).

Los temas del auditor, de la incomprensión y de la soledad del artista ("la incapacidad para encontrar un oyente") que se debaten en la Correspondencia de Benet y Carmen Martín Gaite reaparecen. (Benet; Martín Gaite 2011: 97).

La soledad schubertiana interesa a Benet que se interroga sobre el único arte que no transmite contenido (imágenes o palabras), o sea la música como vector emocional. Para hablar de música, la única opción posible consistiría en captar como el afecto es musicalidad pura, y como por extensión la literatura y el "absoluto literario" o Gran Estilo que Benet quiere salvar, se entremezclan necesariamente con lo musical.

Según Benet, el músico considera la música como un arte dialógico, en este sentido la forma de la sonata por ejemplo coincide con la del diálogo. Durante los primeros años 
de la vida se forma una memoria musical que fija la idea del concierto como interlocución.En vez de adoptar una composición dual orquestra / instrumento que supondría entrar en un modo oposicional en el que se ponen de realce relaciones principalmente antagonistas (pasión / razón, objetivismo / subjetivismo, sociedad / individuo), crea un sistema de valores que implica más matices en la expresión de las incertidumbres del yo, en la interrogación de los valores subjetivos. El objetivo es adoptar una posición introspectiva para despojar la obra de su carácter social y orientarse hacia más intimidad.

Benet observa la modulación schubertiana de las obras creadas a partir de 1824 (Sonata para el piano en La menor (1823), Sonata en La menor $n^{\circ} 16$ (1825), Sonata en Sol mayor (1826), tres sonatas de 1828 escritas algunos meses antes de su muerte, Cuarteto para cuerdas $n^{\circ} 13,14,15$ (1824-26), Quinteto en Do mayor (1828) y Wintereisse), es decir, cómo pasamos de una estructura dialéctica a un soliloquio como fórmula óptima de la intimidad y eso en particular gracias a la pluralidad modal.

Y nos propone un análisis de la Sonata en sol mayor de 1826: en un primer movimiento, dos órdenes intentan instaurar un diálogo clásico, un primer tema expresa el orden del mundo (la voluntad), el tono es solemne, tranquilo, luego enfático y agresivo en una segunda exposición (scherzando). Se introduce después el tema siguiente que representa el mundo del alma y del sentimiento y que se desarrolla de manera independiente respecto al primero. Schubert no adoptó el modo asertivo sino que introdujo una ruptura tonal con los modos interrogativo y dubitativo, los elementos de parodia y de disonancia se oponen al primer tema. El contraste entre voluntad y sentimiento se refuerza para oponer el mundo social al mundo íntimo.El tema central (C) como sublimación del precedente subraya con melancolía el hecho de que la desgracia del hombre forma parte del orden de las cosas.Después ambos temas se separan y el orden inflexible se convierte en una fachada impotente. El movimiento segundo introduce la psique del músico, opera como un "copa transversal" y se orienta del diálogo hacia el soliloquio:

Es [...] un corte transversal por el alma del músico, el diálogo anterior - o intento de diálogo, más bien - se transforma en un soliloquio; unos sentimientos preguntan, otros responden, un temor se insinúa, una esperanza trata de salir a su paso para que cuando se agote surja el canto del desfallecimiento. El músico ha superado la desesperación pero fruto de ella ha quedado ese pozo de desesperanzada melancolía, esa falta de sentido con que tropieza su espíritu cada vez que inicia un movimiento, esa especie de contemplación perversa (sólo con une cierta proporción de maldad es capaz de superar el dolor que le produce) de una voluntad si anhelo, ociosa y desahuciada porque su dueño ya no es capaz de encontrar un objeto que la mueva. (Benet 2003: 109).

Los modos andante, moderato, allegretto, adagio se suceden en un clima de subjetividad cerrada. El primer tema se desarrolla según un modo interrogativo cerrado para afirmar un dolor personal injusto e inmanente sin remedio ni justificación; el segundo reintroduce la voluntad e insta al músico a que continúe su obra. Finalmente, el tercer movimiento adopta los modos allegro, allegro vivace, scherzo, rondo, el músico busca en 
su arte un consuelo y deja de lado su meditación fúnebre para buscar la armonía en los juegos cromáticos y en una forma de impresionismo musical. Velocidad, novedad del tema, gran estilo en oratoria se unen para subrayar un momento fugaz. El arte es una medicina. El tema se detiene y vuelve la melancolía dentro de un clima interior (Ländle) que sintetiza la sonata e introduce un soplo de aire, el deseo de un clima inocente. No se repite el tema, el contraste no puede repetirse ya, el músico sabe que se trata de la emoción de un "hubiera podido ser"que no requiere explicación alguna.

Así que lo que propone Benet cuando analiza la composición schubertiana, es finalmente la partición contada del conflicto de dos órdenes mundanos. La modulación afectiva de una mutación de los sentimientos que desemboca en la renuncia. Benet traduce lo musical en idea hasta el cierre completo como emoción pura. O sea los módulos sucesivos:

Las cosas son como son, el mundo es como es.

Y siendo el mundo como es está bien que así sea.

¿De qué sirve tal orden al hombre desgraciado?

Estando las cosas así ¿de qué sirve hacer nada. Y puesto que existe un orden externo, qué finalidad puede tener el desorden del alma?

Has de seguir tu obra [...] no porque sirva de algo ni porque el mundo [...] te lo vaya a agradecer sino porque es el único procedimiento para acallar el dolor y distraer la desesperación.

Es cierto, hay un consuelo en el arte; pero qué otra podría ser esta alegría de haber seguido las cosas como en un entonces.

Sabido es que este mundo es un valle de lágrimas.

Benet considera que es el mismo proceso que va a repetirse bajo diferentes formas dialogadas en las últimas obras de Schubert. Apunta que mientras el músico va avanzando hacia la muerte, el estilo se hace más puro para ir hacia una forma única, en la que los contrastes de tonos acaban por desaparecer, en la que el claroscuro y las transiciones se borran: subjetividad y objetividad se unen en la renuncia. En el Quinteto en Do mayor et la Sonata $n^{\circ} 21$ (1828), el antagonismo se eclipsa y el dolor lo invade todo; el mundo ya no es más que un valle de lágrimas:

La resignación se mide en esa aproximación de los temas contrastados, esa desaparición del antagonismo, pareja al acomodo final que encuentra la voluntad en su condición más miserable. Perdida toda desesperanza es superada la desesperación y en ese clima de soberana beatitud el músico logra encontrar cierta perversa satisfacción en esa paz tanto más completa cuanto más ahonda en la aniquilación y en el alejamiento de la siempre y horrenda motivación (Benet 2003: 110)

Al final de la noche fría: en el viaje interior de Wintereisse, todo se convierte en una proyección, un paisaje mental donde se mueven lentamente los sentimientos. Lo de afuera solo existe por lo de adentro. La obra de Schubert se ajusta a la filosofía de 
Schopenhauer al pasar del tiempo a la atemporalidad desvelando la presencia de una única idea, de un modelo general idéntico que subyace a las cosas. Cuando se desvela la Idea, el tiempo desaparece y cada instante se vuelve eterno. Richard Wagner afirma que en Schopenhauer la música no representa las ideas contenidas en los fenómenos, sino que constituye en sí misma una idea total del mundo idónea a la música (Sans: 139). En realidad, para Schopenhauer, la música no representa las ideas como lo hacen todas las otras artes, sino que es la manifestación directa de la voluntad. Por otra parte este tipo de análisis conduce la música sobre el camino de la metafísica. Permanecería, envuelta en la música, una idea descifrable: por consiguiente el lenguaje musical universal no se limita al fenómeno sonoro, pone de realce un inefable y se dirige no sólo a la sensación sino también al pensamiento, a la razón. Sin embargo, ese enfoque parece reductor. Finalmente lo que prevalece, y el escritor insiste en este punto, es la idea de evolución continua.

¿No podríamos pensar que lo que quiere decir Benet cuando "explica" Schubert, es que empieza a librarse de la forma de la sonata? Cuando insiste sobre los tonos, las tesituras, los ritmos, Benet no parece querer evocar cuestiones de formas sino más bien la emergencia de un tiempo "no pulsado" (según la fórmula de Deleuze) que deriva de una proliferación de velocidades y lentitudes.

Depende de cómo se mire y de si se privilegia el plano de la organización o el plano de la consistencia. Así que es posible destacar dos lecturas de la sonata, una primera que hace hincapié en el significado (las ideas, los universales), y la otra en la intensidad. Benet quiere realizar ambas lecturas de manera concomitante. Por otra parte, cuando escribe que la música no tiene contenido, hay que aclarar lo que quiere decir. No basta con aducir que la música no "cuenta" algo, lo hace, pero de una manera específica. El contenido existe, y es lo que explica Benet cuando afirma que Schubert enuncia ideas y traduce la sonata en un encadenamiento de módulos de afectos relativos a ideas. Existiría algo así como "personajes musicales" que podrían designar,con una asociación subjetiva de ideas, afectos. Por otra parte, Benet intenta penetrar la materia sonora pura y articular ambos niveles.Escucha la música de manera individual como una fórmula que remite a sentimientos, y en este sentido percibe lo que le interesa. No obstante, no se trata de considerar que la música tenga como contenido ideas en el sentido en que se espere aprehender una idea real mediante la memoria o la imaginación (es decir que Schubert buscara traducir en música una idea concreta), se trata de hacer música, de inventar y la cuestión misteriosa es cómo ocurre exactamente.

\section{Benet y la música}

Quizás sea seguro asumir que esta inmersión en el soliloquio como desesperación pura mediante la superación de la dialéctica que Benet observa en Schubert tiene que ver con el espíritu de un escritor que busca oír su propia música. Por otra parte, la resignación que se observa en las últimas composiciones de Schubert casi coincide con la que se expresa en los soliloquios, las variaciones dialogadas y los monólogos de los personajes benetianos y en particular en el lirismo de Saúl ante Samuel donde entra en escena de 
manera evidente la modulación vocal, modal y tonal negativa y continua que participa de la expresión de la resignación de los personajes.Así basándose en la negación y en la modulación permanente de la polaridad de la frase, Benet va a entrar en un trabajo de forja como si se tratara de generar un desarrollo continuo de la forma así como una variación continua de la materia: "Pues la variación es sistemática en el sentido en el que los músicos dicen que « el tema es la variación »" (Deleuze; Guattari 1996: 97).

Esta variación continua permite que los componentes de la frase,que también tienen una dimensión sonora, entren en un continuum creador. En algunos casos, se puede alcanzar un extremo en el que esta variación continua es demasiado intensa: toda forma estable se descompone. El flujo frástico dominado por el monólogo, el soliloquio - una palabra que no se dirige a nadie, una voz arrojada al vacío - se convierte en un material sonoro muy elaborado que genera relaciones diferenciales de lentitud y velocidad de "pura intensidad" que derivan de la disolución formal que se observa. Guattari y Deleuze evocan a Nathalie Sarraute que en L'ère du soupçon,

propone por su cuenta un clara distinción entre dos planes de escritura : un plan transcendente que organiza y desarrolla formas (géneros, temas, motivos), que asigna y hace evolucionar sujetos (personajes, caracteres, sentimientos); y otro plan completamente distinto que libera las partículas de una materia anónima, las hace comunicar a través de la "envoltura" de las formas y de los sujetos, y solo mantiene entre esas partículas relaciones de movimiento y de reposo, de velocidad y de lentitud, de aspectos flotantes, de tal forma que el propio plan se percibe al mismo tiempo que nos permite percibir lo imperceptible [...]. (Deleuze; Guattari 1996: 270).

Sarraute muestra como Proust por ejemplo, está dividido entre los dos planes, en la medida en que extrae de sus personajes "las materias ínfimas de una materia impalpable". Recoge todas sus partículas en una forma coherente, las introduce en la envoltura de tal y tal personaje.

Se convoca la dimensión intensiva al someter todos los componentes de la frase a una variación intensa y continua. Se entra en una forma de temporalidad calificada de "no pulsada" en la que lo más importante no es un tiempo preorganizado sino el desarrollo de una voz monologada que crea la temporalidad y que realiza una duración. La duración consistiría aquí en una diferencia de cualidad, una alteración permanente que no se puede medir. A modo de ejemplo Benet explica que Saúl ante Samuel es un relato obsesivo que trabaja sobre la variación de una idea X, llamada tónica:

Todo es una encrucijada mental de alguien que lleva cuarenta años dándole vueltas en la cabeza a una idea obsesiva, la espera, la incierta espera de quién nunca está lleno, de alguien que dejó de ser un homo faber hace ya mucho tiempo.Retomé una idea central equis y no la dejé hasta el final: esa fue la tónica.” (Benet 1997: 186)

La tónica se refiere al plano de organización, la parte estable, el punto de atracción, el sistema fijo de coordenadas al que se somete el movimiento. La nota tó- 
nica permite establecer la gama. En Saúl ante Samuel, un evento X se cuenta de diferentes maneras y con diferentes tonalidades. Si Benet utiliza la forma de un soliloquio, o de falsos diálogos donde se pueden oír voces múltiples, es porque opta por la forma que le permite mejor desarrollar la pluralidad tonal y modal. Explica que si el lenguaje de las ideas puede ser atonal sin perder su significado, el lenguaje oral no puede funcionar de la misma manera. La frase y su verdadero significado intencional siempre dependen de un tono preciso. Lo que se llama tono se refiere a la prosodia del conjunto de la frase. Entonces, Lo importante no se limita a la organización sintáctica sino que hay que tomar en cuenta las disposiciones sonoras y musicales de acentos y espacios.

Es la tonalidad la que permite a Benet entrar en la música. En Schubert la oposición voluntad / dolor se difumina porque abarca todos los tonos y se disuelve en una honda resignación. En Saúl ante Samuel, la dialéctica sigue siendo al origen del drama.Todo reside en el antagonismo. Totalmente antitético por las estructuras sintácticas negativas que desarrolla, el estilo refuerza la oposición genealógica de los unos respecto a los otros: los dos hermanos, el hijo legítimo y el bastardo, los padres y los hijos, tú y nosotros (Benet 1994: 193). El litigio que tiene lugar (como caso familiar, nacional) no puede concluirse ya que se trata de estructurar la queja, el reproche, el rencor bajo la forma de un vano llamamiento, de series de preguntas cerradas, del falso diálogo, de una modalidad dubitativa constante. La función fática construye una relación reflexiva y analítica que se dirige hacia la emergencia de una verdad inaccesible y pone de realce con su intensidad impotente puntos que son objeto de repetición especial, como por ejemplo la discordia de los hermanos, el adulterio, el sufrimiento o episodios de la guerra civil presentados por Martín y Manuel, el alcalde de Región (Benet 1994: 178, 224, 208).

¿Qué resultado cabe esperar? pregunta ¿el triunfo de nuestras armas? ¿Qué triunfo es ése? Le responde el otro. ¿De qué me estás hablando, no te estarás confundiendo? ¿Nuestras armas? ¿Qué armas son ésas? No sabía siquiera que tuviéramos armas; díme ¿armados nosotros? ¿No habrás perdido el juicio? [...] No creas nada de lo que dicen, le responde; ni siquiera estoy seguro de que esta guerra, de la que tanto alardean, se esté produciendo realmente. ¿Te das cuenta que a los viejos intentan engañarnos en todo momento, como si quisieran ocultarnos nuestra misma vejez, nuestro desvarío y la proximidad de nuestro fin? [...] Yo no creo nada y recelo de todo, es lo único que cabe a nuestra edad; no me creo nada. [...] no creo nada de lo que dicen $[\ldots]$ No doy ninguna importancia a nada $[\ldots]$ ¿Nuestros enemigos? ¿Pero de qué estás hablando? ¿estás en tu sano juicio? ¿Nuestro triunfo? ¿No ves que en nuestras vidas ya no queda sitio para ninguna clase de triunfo? ¿No ves que no cabe? Escucha siéntate; ven acá. ¿Y el triunfo de nuestros enemigos? Los que sólo quieren vengarse (Benet 1994:168).

Pero la oposición suena falsa. La negación que somete cada frase a una presión interna estéril o indica el rechazo ya no funciona como motor de contraste, se convierte 
en una sustancia, un tejido. Entonces, los tonos se nivelan, la negatividad se convierte en una expulsión oral irreprensible, verborrea, calada. El ritmo y la cadencia se aceleran. A este propósito Carmen Martín Gaite utiliza la palabra de "vomiteo" para evocar la especificidad de los diálogos deshumanizados inventados por Benet en su primera novela Volverás a Región:

[...] Juan Benet [...] ha tenido la valentía de vomitar para afuera, no en vomitaderos secretos, de sacar todas esas tripas a la luz y dejarlas ahí culebreando, gritando, clamando la abertura y el oreo de todos nuestros polvorientos desvanes. (Martín Gaite: 2002:113)

Este flujo asombroso reduce el interlocutor al papel accesorio y pasivo de testimonio. Este ensimismamiento traumático que corresponde a la expresión exclusiva de un pasado cuya eliminación se desea no hace sino aumentar el odio. La catarsis no se realiza. Diferentes elementos participan de este movimiento que convoca un destinatario al que no se ofrece ninguna dimensión performativa. En el caso de Simón se puede observar un desdoblamiento de la conciencia repetitiva: primero, la tendencia a multiplicar los imperativos negativos bajo la forma de listas. Segundo, la multiplicación de preguntas cerradas y negativas bajo la forma de la lista o de la enumeración. Las preguntas siguen en el aire, caen en el abismo, un vacío que suena como una confesión de impotencia para detener la repetición de lo destruido y el movimiento de lo destructivo. De la misma manera, la acumulación de preguntas puede significar que se impone un orden negativo. Abundan los ejemplos. Al principio del relato, Simón inquieto y postrado no quiere abrir la puerta de la casa. La pregunta ¿Por qué abrir? equivale a decir, no abra la puerta, no abra la ventana, jamás: las preguntas cierran definitivamente la apatía y el enclaustramiento elegidos por el protagonista, como lo comprendemos en toda la parte central del relato:

No salgas; no vuelvas a abrir la ventana, corre el visillo. No te muevas; observa tu manos y de para qué valen »; « ¿Para qué vas a abrir? ¿Por ventura le vas a preguntar qué ha sido de él todos estos años? ¿Dónde ha vivido? ¿Cómo? ¿Si se casó? ¿Si al fin encontró al gato? ¿Quién disparó sobre su hermano? No abras, no llames a nadie. (Benet 1994: 110,115)

Las preguntas acumuladas durante páginas, según el modelo de la repetición periódica no indican el menor diálogo, al contrario permiten reforzar la dimensión declamatoria del texto. Lo que se presenta como afirmación o negación según el caso y jamás como pregunta, sólo desemboca en un repliegue máximo del lenguaje en lo callado, en lo implícito. En otros términos, incluso cuando se enfrentan ambos personajes, no se trata de producir una reacción, de suscitar una adhesión cualquiera sino de entrar en la proclamación para aumentar la intensidad lírica del texto. 


\section{Conclusión}

La obra de Benet es la afirmación pura de un significado negativo, expone una metaficción trágica. La música convoca los perceptos y los afectos más allá de la razón y el sonido de Benet está hecho de las voces de criaturas resignadas que entran en resonancia, construyen las condiciones de la interlocución y se plieguen sobre sí mismas para dar a oír en el interior y desde el interior, la más pura soledad.

La voz se expulsa y se queda sin recepción, la liberación es imposible. Así, Benet quiere alcanzar al lector que pueda escucharle, éste va a seguir el movimiento de una vocalización íntima para unirse a su vez al sonido de su propia voz. No se prevé otro dispositivo. Esta voz resignada no puede dirigirse a alguien en particular, por eso nos afecta a todos.

\section{BIBLIOGRAFÍA}

BENET, Juan (1994): Saúl ante Samuel. Madrid: Cátedra.

(2003): Puerta de tierra. Barcelona: Seix Barral.

(1982): La moviola de Eurípides. Madrid: Taurus.

(1997): Cartografia personal. Madrid: ediciones Cuatro.

BENET, Juan y MARTÍN GAITE, Carmen (2011): Correspondencia. Barcelona: José Teruel, Galaxia Gutenberg.

DELEUZE, Gilles; GUATTARI, F. (1996): Crítica y clínica.Valencia: Editorial Pretextos.

(1980): Mil mesetas, capitalismo y esquizofrenia.Valencia: Editorial Pre-textos.

DELEUZE, Gilles y PARNET Claire (2013): Diálogos. Valencia: Editorial Pre-textos. MARTÍN GAITE, Carmen (2002): Cuadernos del todo. Barcelona: Editorial Maria Vittoria Calvi.

SANS, Edouard (1969): Richard Wagner et la pensée schopenhauerienne. Paris: Klincksieck.

SCHOPENHAUER, Arthur (2014): Le monde comme volonté et comme représentation. Paris: PUF.

\section{PERFIL ACADÉMICO Y PROFESIONAL}

Sandrine Lascaux es profesora e investigadora de literatura en la Universidad de Le Havre (France). Ha publicado varios artículos y dos libros sobre autores españoles y franceses (Seuils, Orbis Tertius, Villeurbanne, 2017; Le chagrin et le néant, Villeurbanne, 2018. Es especialista de las articulaciones entre la filosofía y la literatura, especialmente los filósofos de la "French Theory". Es miembro regular y co-directora del GRIC en Le Havre.

Fecha de recepción: 21/05/2019

Fecha de aceptación: 05/07/2019 